\title{
Studies on ready to serve (RTS) beverage from dragon fruit
}

\author{
Virendra Foke*, Amit Zambare, Dipak M. Gaikwad and Nikhil Alhat
}

Shriram College of Agricultural Engineering, Paniv, Solapur (M.S.) India

Email : virendrafoke@gmail.com

\section{SUMMARY:}

The present study attempted to develop a RTS beverage using dragon fruit. Preliminary investigations were carried out based on the standards specified for RTS fruit drinks to develop a suitable recipe. RTS beverages were prepared containing four levels of dragon fruit juice $(8 \%, 10 \%, 12 \%$ and $14 \%)$, citric acid $(0.2 \%, 0.3 \%, 0.4 \%$ and $0.5 \%)$ with 12 per cent sugar and 0.01 per cent potassium Meta bisulphite. Sensory evaluation was conducted using 25 untrained panelists to determine the best juice concentration to develop the RTS. Proportion with 12 per cent dragon fruit juice and 0.4 per cent citric acid was selected as the best level for the development of dragon fruit ready to serve beverage. Storage study for analysis of acidity, TSS, ascorbic acid and $\mathrm{pH}$ from 0 to 50 days was investigated for the prepared beverage at a regular interval of ten days. A slight increase in acidity and TSS and decrease in $\mathrm{pH}$ and ascorbic acid in samples stored at room temperature was observed.

KEY WORDS : Dragon fruit, RTS, TSS, Acidity, pH, Room temperature

How to cite this paper : Foke, Virendra, Zambare, Amit, Gaikwad, Dipak M. and Alhat, Nikhil (2018). Studies on ready to serve (RTS) beverage from dragon fruit. Internat. J. Proc. \& Post Harvest Technol., 9 (2) : 55-59. DOI: 10.15740/HAS/IJPPHT/9.2/55-59. Copyright@ 2018: Hind Agri-Horticultural Society. 